\title{
The Risk Assessment of Occupational Exposure to Chemical Substances by Use of a Global Product Strategy Method in Oil Refinery Industry
}

\author{
Akbari Jafar ${ }^{1,2 *}$ and Moradi Rohoddin ${ }^{1}$ \\ ${ }^{1}$ Health, Safety and Environment Administration (HSE), Abadan Oil Refining CO, Iranian \\ National Oil Refining \& Distribution Company (NIORDC), Iran \\ 2Department of Health, Safety and Environment (HSE), Isfahan Province Gas Company, \\ National Iranian Gas Company, Iran
}

Research Article

Volume 2 Issue 4

Received Date: June 02, 2018

Published Date: July 16, 2018

DOI: $10.23880 /$ eoij-16000165

*Corresponding author: Akbari Jafar, Health, Safety and Environment (HSE) Administration, Abadan Oil Refining Co, National Iranian Oil Refining \& Distribution Company, Abadan, Iran, Email: akbari.jafar@gmail.com

\section{Abstract}

Introduction: In order to implement an effective risk management program and RPP (respiratory protection program), assessing the risk of occupational exposure to chemicals in the workplace is necessary. The aim of this study was to evaluate the risk of occupational exposure to chemicals by using GPS (Global Product Strategy) provided by the ICCA (International Council of Chemical Associations) in various operational units of the refinery in Abadan.

Material and Method: This study is descriptive-analytical. After determining the SEG (similar exposure groups) collect information about the process, maintenance, occupational groups and tasks, chemicals, priority and determine the status, chemical exposures, compounds BTEX (benzene, ethyl benzene, toluene and xylene) as well as hydrogen sulfide, respectively, using standard methods NIOSH 1501 and NIOSH 6013 were sampled. The mentioned items are as follows; process, maintenance, occupational groups and their tasks, chemical substance, prioritizing and determining the condition of exposure to chemicals and BTEX materials. Then, based on exposure rates (ER) and hazard classification (HC), describes qualitative risk classification (RC) was describing. The relation risk classification rate and respiratory function reduction and respiratory disorders were studied by t-independent test and through SPSS (version 20).

Results: The risk of exposure to benzene in the operating units was higher other materials. Such that in some units, including ROP, distillation 100, CR1, distillation 70, of MTBE and NTA quality scores 1A (the highest possible), respectively. After benzene, the highest risk score substances (hydrogen sulfide, ethyl benzene, toluene and xylene), respectively. Exposure risk rate, in other units, was assessed in the first and second level of priorities and the suitable measures (red and yellow zones) were done. It was also found that a significant relationship the risk and respiratory rate were statistically lower $(\mathrm{P}<0.009)$. 


\section{Ergonomics International Journal}

Conclusion: The results indicated that the risk of exposure to benzene Items investigated was high. The units ROP, CR1 and distillation 100 had the highest risk score. The results showed that the risk quality $1 \mathrm{~A}$ (red area) for benzene in the unit NTA, MTBE, distillation $(70,100)$, CR1 and hydrogen sulfide were found in Kat Crocker. Among the substance, benzene has the highest risk score is qualitative.

Keywords: Risk Assessment of occupational exposure; ICCA; GPS; RPP

\section{Introduction}

Although the chemicals are each a useful in our daily life, but because of the negative effects on human health and the environment their exposure to the causative costs [1]. To avoid the harmful effects of these chemicals, control and corrective actions when working with them is of great importance [2]. To achieve health objectives for the protection of the work force, it is necessary that exposure to chemicals and risks of these substances to be investigated [3]. For the decisions about control measures and protect employees against the adverse effects of chemicals, the health risks caused by exposure to this material specifically be evaluated [2]. Key solutions for the evaluation of environmental risks associated with exposure to chemical risk assessment process [4-6]. Health risk assessment to determine the level of exposure to toxic chemicals and the risk of these materials, as well as enables us to make appropriate decisions for the measures needed to protect "its" people. Without risk, there may be less important time and resources to spend risks and substantial risks to be neglected [7]. In Iran, a few studies of occupational exposure to chemical risk assessment. In all the studies provided by the Singapore Institute of Occupational Safety and Health were used [8]. Including studies can be studied Jahangir's was on "Occupational exposure to chemical risk assessment order to provide control measures" in the polyurethane foam industry mentioned $[9,10]$. The risk of exposure to seven chemicals, including toluene Isocyanate, polyethylene glycol, polypropylene glycol, ethylene diami ne, cut acetate (Cosmos), methylene chloride and calcium carbonate was evaluated. In this study it was found that the above mentioned operators the highest risk jobs foam manufacturing toluene isocyanate (operator cutouts), respectively. It was also found that occupational exposure to this material reduces the volume and lung function in workers.

Other studies include study Jahangiriy and motevaghe's [11] on the "health risk assessment of exposure to harmful chemical agents," mentioned the petrochemical industry [11]. In this study it was found that employees investigated during his career with 10 chemicals, including methyl ethyl ketone, epichlorohydrin, phenol, sulfuric acid, chlorobenzene, toluene, isopropanol, methylene chloride, hydrochloric acid and acetone were exposed. The materials are exposed to the risk rating of epithelial chloride dimenhydrinate in the operation of the reservoirs and utility jobs and repairs maximum and then with epithelial chloride exposure and exposure to methyl ethyl ketone dimenhydrinate technical inspection job in the operation of the reservoirs and utility jobs the highest risk exposure, respectively. The study authors conclude that using the information on the risks and results of measurement and evaluation of chemical agents within the structures of health risk assessment of exposure to chemical pollutants can be harmful different occupations of the face of chemical ranking that results can be prioritized in the allocation of resources to control measures and reduce the level of exposure risk to an acceptable level to be used. Another study by Golbabaei's, et al. [12] that to assess the health risks of exposure to chemical pollutants with emphasis on the risk of leukemia was conducted for the petrochemical industry [12]. In this study it was shown that benzene, with risk factor gained $4.5-5$ risk levels 5. It proves that controlling measures for this harmful and carcinogenic chemical substance should be done as soon as possible [12].

In order to risk assessment of exposure to chemicals from the organizations or countries' different risk assessment methods are provided. Some of these methods can be the Organization method EPA, exposure risk assessment, Japan, Singapore, WHO (World Health Organization) the Organization OECD and more. To manage and control the side effects of their chemicals, ICCA (International Council of Chemical Associations) the Organization in the program GPS (Global product strategy), the risk assessment in the form of a guide entitled "Guide ICCA for risk assessment of chemicals "presented [13]. This risk assessment is based on three "risk characterization, exposure assessment and 


\section{Ergonomics International Journal}

risk descriptions" to assess the risk of exposure to chemicals. Accordingly, the obtaining rate of risk of exposure to chemicals, based on the level of risk exposure identified and control measures are defined and implemented. The oil refining industry because the purification and production of oil derivatives, has always been a high risk for occupational exposures to chemicals are created. So that's always harmful chemical agents in the workplace as a crucial factor in such environments has become. Occupational exposure to these chemicals to expose one's to negative side effects, including respiratory, skin, blood, kidney and puts. Therefore, the implementation of measures to control occupational exposure to these substances and to define corrective actions and control is a necessary and urgent. The purpose of this study is to obtain risk of chemical exposures, the risk of occupational exposure to chemicals (consumer, intermediate and output) are available in different units operating Abadan Oil Refining Company.

\section{Materials and Methods}

\section{Used Risk Assessment Method}

This study is descriptive - analytic. After determining the similar exposure groups (SEG), collect information about the process, maintenance, occupational groups and tasks, prioritize and determine the status of chemical exposures, for the following reasons this 5 substances for risk assessment of exposure to chemicals were chosen:

- According to research, BTEX compounds at the highest concentrations of volatile organic compounds (VOCs) have. From these 4 matters, Toluene has the highest concentration. The controlling measures must take priority for this component [14].

- The threshold limit value for this substance (on the basis of an acceptable TLV health center and work environment Department of Health and Medical Sciences) from 0.5 for the benzene, $100 \mathrm{ppm}$ for xylene is variably defined. By applying the correct application controlling measures for this range of products, other chemicals in the pain and higher Co production of the controlled substances.

- BTEX compounds the negative effects on the health of their people, have has always been regarded as a concern. Each of these compounds and hydrogen sulfide serious effects on the health of their employees.

- BTEX compounds and hydrogen sulfide each has different effects on the various organs, including blood, peripheral and central nervous, respiratory air. Therefore, measurement, evaluation, and control is especially important.
- Due to lack of adequate facilities available (including devices GC-MAS) possible to identify all the chemicals that persons exposed to them does not provide. So try to Risk assessment and management exposure to BTEX compounds and $\mathrm{H} 2 \mathrm{~S}$ indirectly reduce exposure to a wide variety of chemicals.

- This method can be used exposure specific source the substance. But for the prevention and control substances that are combined (such as poly aromatic hydrocarbons or volatile organic hydrocarbons) by calculating the risk rate for the each material and taking the higher risk rate to apply controlling measures, can be used as a reasonable way and with procedures to be used more rationally.

Methods of risk assessment of occupational exposure to chemicals present derived from the guidance provided by ICCA in the GPS program for risk assessment of exposure to chemical substances [13].

The risk assessment method presented in the form guide risk assessment by the ICCA has considerable advantages for use in assessing the risk of occupational exposure to chemicals, such as the advantages are as follows:

- The basic method has better, more accurate and more comprehensive risk assessment (risk characterization) chemicals. So that more of Hazardous chemicals such as acute toxicity (skin / digestive / respiratory), corrosion / irritation, eye irritation, sensitization, mutagens / carcinogens, repeated dose (Skin / digestive / respiratory), reproduction / expansion (skin / ingestion / inhalation), environmental, chemical and physical hazards as part of table columns specified by scoring from 1 to 4 are considered.

- In this method is the direct role of occupational exposure to chemicals applied to assessing the risk of occupational exposure and as well as other methods, such as provided by the health and safety of Singapore, need to use mathematical formulas to obtain exposure No chemicals.

- This simple and rapid method for assessing the risk of occupational exposure to chemicals. When you need a process to be evaluated quickly and accurately, easily handling the chemicals and the amount of exposure can be a risk assessment carried out by occupational exposure.

- It is presented in three parts and eight stages of the process are summarized as follows. Figure 1 shows the eight-step risk assessment process GPS. 


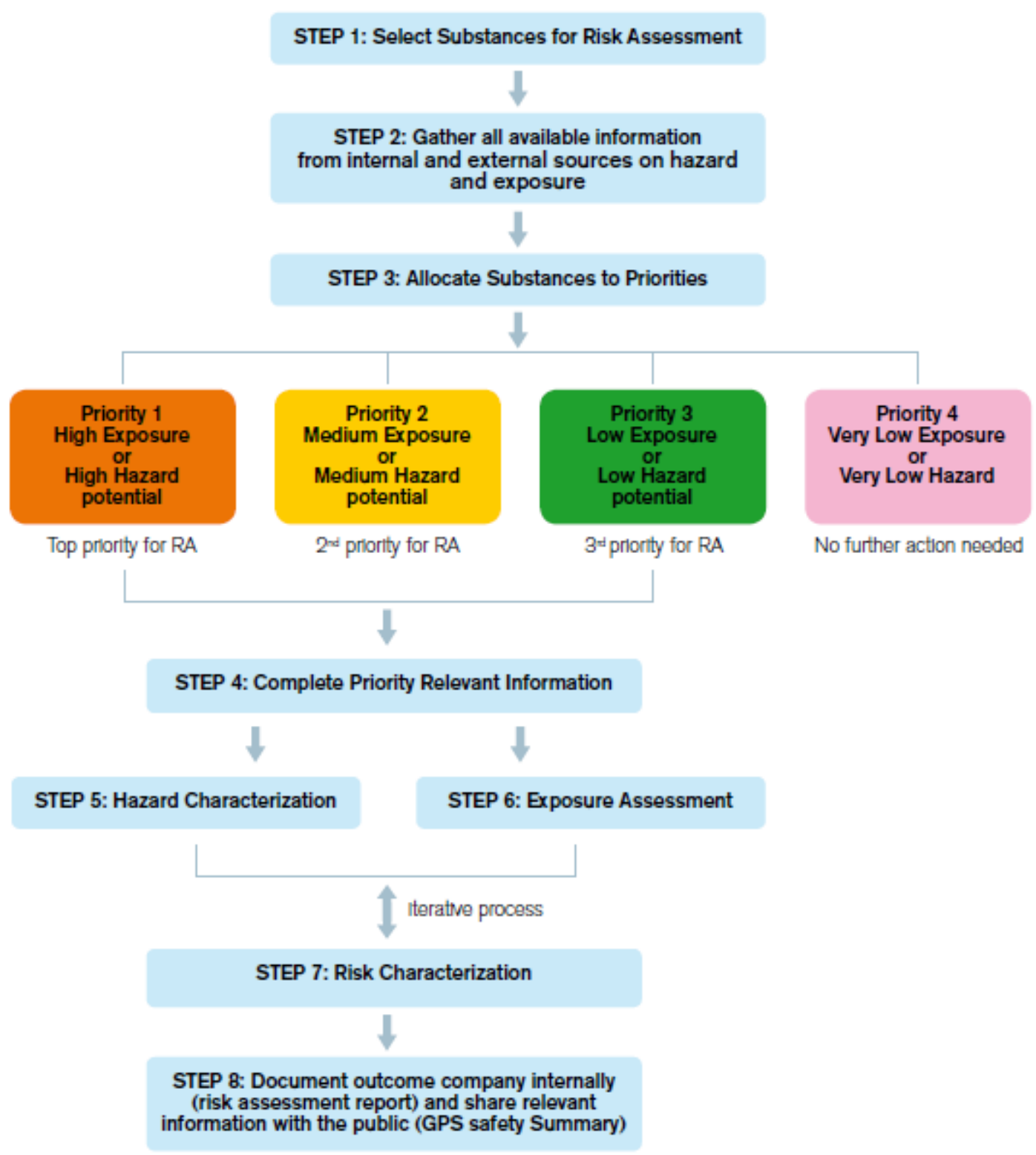

Figure 1: Steps risk assessment for GPS.

Part I: Basic Specification

Step One: Exposure Assessment Strategy

Develop a strategy for occupational health risk assessment with the introduction of a risk assessment, goal setting and evaluation of development programs (in order to document the risk assessment) begins.

Step Two: Gather Information

The initial topic of includes the selection of basic data collection and work activities (for example, exposure scenarios) facilitates to complete the exposure assessment. This step includes the process of data collection; data maintenance, workforce (manpower), chemicals, risk information and OEL, and the details of monitoring data are exposed.

Step Three: Allocate Substances into Priorities

Exposure assessments must be in the group of workers work in the same or similar activities are similar to the consistency of potential exposure to hazardous 
substances in the workplace that have been placed, have done (such as similar exposure groups). For this purpose, organizational charts (to determine SEG), the scope of work (identify more efficient work areas are typically identified based on existing operations areas), activities / tasks (detect activities / tasks with higher exposures or close values OEL), and chemicals that workers may be exposed to them, are investigated.

\section{$>\quad$ Part II: Risk Assessment}

Step Four: Develop Priority-Relevant Information ("Base Set of Information")

According to the information gathered during the specification step basis, a list of SEG, duties and chemicals (for example, exposed scenarios) for the assessor to conduct an analysis of exposed must be completed. The analysis includes determining the intensity of exposed to a chemical exposed at work or activity to be "compare with" the OEL is defined. This is step includes the step of determining the exposed scenarios for SEG, as does the intensity of exposed rates for each scenario.

Step Five: Characterize Hazard

Before determining the hazard characterization, exposure rate and the risk assessment, the assessor must decide on priority chemicals for risk assessment. Figure 2 decisions about priorities for risk assessment shows exposure. The aim of priority substances, deciding about the first of which is a substance of risk assessment. Chemicals with high risk or high exposure potential should be evaluated first.

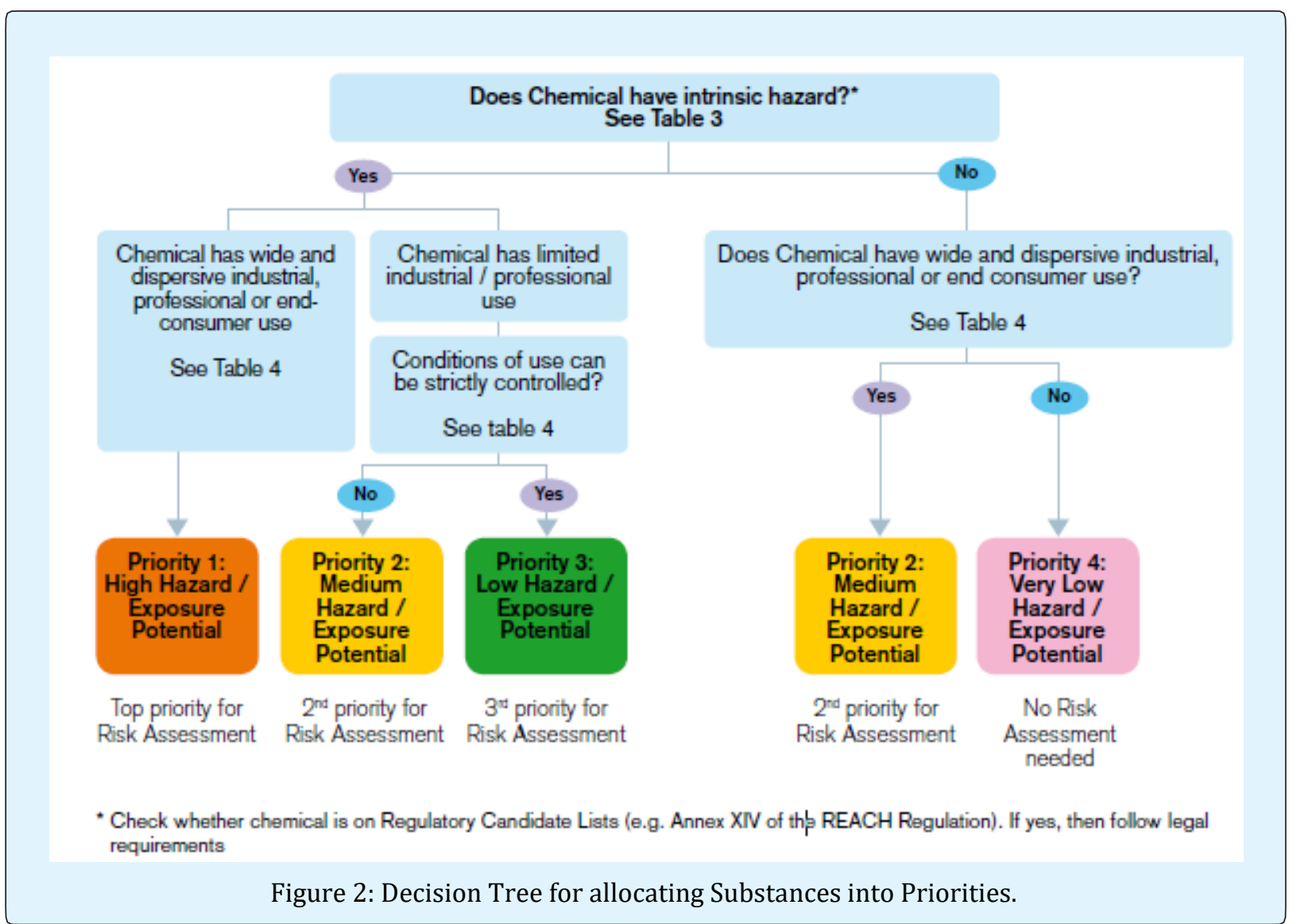

Step Six: Assess Exposure

A health risk assessment of exposure to the drawing task and concern caused by the material, with descriptions of the substance in the form a risk matrix can be done. Rate risk, exposure and risk stratification based on the consequences shall be. Risk is assessed on a priority basis to determine follow - up actions.

\section{$>\quad$ Part III: Conduct Risk Characterization}

Step Seven: Risk management Category (RMC)

Risk Management Category (RMC) the prioritization of potential occupational health risks associated with exposure workplace provides. RMC to determine if existing controls are enough or need to improve are used. RMC also as a communication tool and to plan future 


\section{Ergonomics International Journal}

work extra (such as air monitoring, prevention, testing, engineering controls, the reliability of the procedure contains steps to minimize exposure, etc.) used. The operations related to RMC are shown in Figure 3.

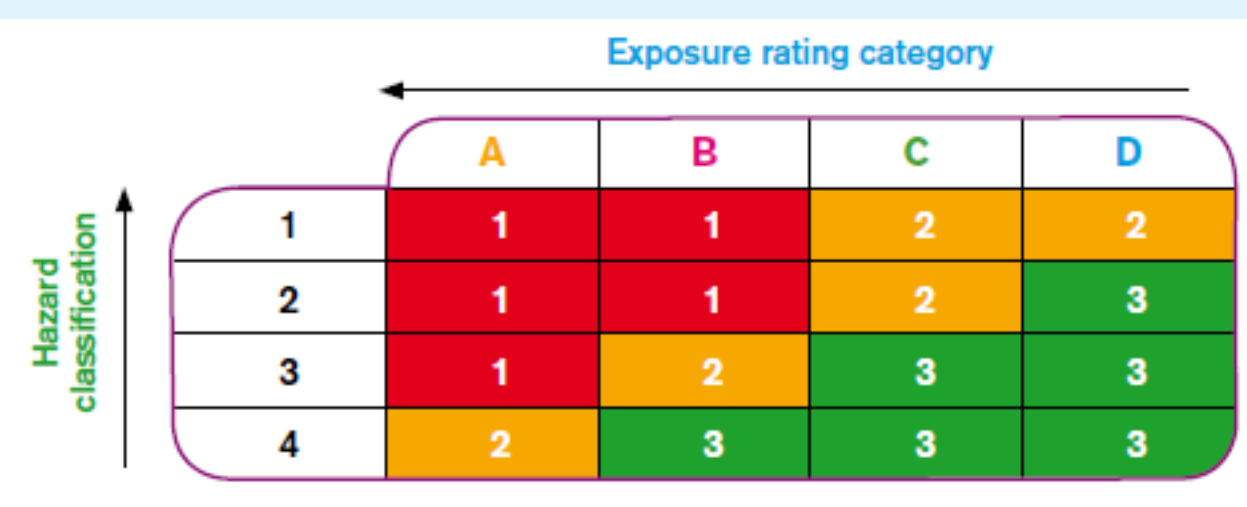

$$
\begin{aligned}
& \text { Red }=\text { confirm controls } \\
& \text { Yellow }=\text { continuous improvement } \& \text { ongoing monitoring } \\
& \text { Green }=\text { periodic reassessments }
\end{aligned}
$$

Figure 3: Risk management category (RMC) based on exposure rating category and risk classification.

\section{Step Eight: Risk Control}

Finally, the hierarchy of controls to reduce the risk of occupational exposure to chemicals defined. Risk control measures are as follows:

- Removal or replacement processes, equipment or that raises exposure.

- Engineering controls (such as encapsulation, local exhaust ventilation, etc.).

- Control of working methods (such as using wet methods to suppress dust) and staff training.

- Management control (such as limitations or to change jobs order to reduce exposure of workers).

- Suggesting the selection, fit and use of personal protective equipment.

\section{Sampling and Studied People}

Abadan oil refinement is the largest one in Iran, which is located in Abadan city, Khuzestan province. The refinery over 400,000 barrels per day of oil and oil derivatives (including naphtha, gasoline, diesel, solvents and various special cases) and in the refining area over 8,000 troops Occupational exposure to chemicals in all units puts persons at risk of adverse health effects.

The BTEX compounds for sampling in standard operating environments NIOSH 1501 method were used. First, terms of several people working on each unit, the many samples were determined. Absorber tube samples using activated carbon (activated carbon produced from coconut charcoal used in this study had a mean particle size of, approximately, $6 \times 70 \mathrm{~mm}$, purity over 99.5 of 20/40 mesh size building Merck Germany (Merck) with laboratory grade high purity, were used) and the consumption is 0.2 liters per minute for 15 minutes to 8 hours were collected. The samples using gas chromatography with FID detector were analyzed. In addition to sampling of hydrogen sulfide, the NIOSH 6013 method was used standard. All the sampling and analysis was done by the standard method. To control the confounding effects of wind speed, all samples in calm weather conditions with minimal air flow rate $(1.0$ meters per second) was carried out using a vane anemometer wind speed assessment and sampling was controlled conditions.

\section{Statistical Analysis}

The data from the study, using SPSS, version 20 were analyzed. To determine the mean and standard deviation data, descriptive statistics were used and the mean exposure of individual samples was "compare with" between units. In order to analyze the relationship between individual exposure to chemical risk score and reduced lung function independent t-test was used. For this purpose, the results of spirometry test 
subjects in year 2015 cases of occupational examinations were extracted and analyzed the frequency of three factors FVC, FEV1, FEV1 / FVC was used.

\section{$>\quad$ Findings}

- The information about processes, maintenance, chemicals and determination of similar exposure groups: The occupations and their defined tasks were collected from different operational units by use of designing check list, interview to the managers, reviewing organizations diagrams and charts. Afterwards, the site staff group (site man) was determined as similar exposure group (SEG) to measure and sample chemical for assessing exposure risk.

Since this group of persons was present in operational units within three different shifts of work and, at the same time exposed to chemicals, each were targeted as the studied cases for risk assessment. Implementing controls measures for the mentioned people in operational sites and by decreasing or removing exposure to chemicals the condition of exposure to standard amounts and less permitted limitations, were provided in the units. So, the exposure to chemicals for those personnel's were present periodically or in a short period, was at the standard level or less fat.

- Measuring occupational exposure and determining exposure rating: By use of the check list provided primarily chemicals concluding chemicals information, their hazards, the several exposed people, occupation (task those associated with chemical, exposure duration, exposure process and present controlling measures), interview to units managers and staffs and also by use of previous measuring results (three previous years), the chemicals being possible the staffs exposed to them were recognized and also documented to be prioritized and measured.

Finally, by studying different substances in petroleum compounds (including consumption, interstitial and production), consumables and other substances to assess risk exposure and determine the combined risk of BTEX (benzene, toluene, ethyl benzene and xylene) and hydrogen sulfide was selected. Determination of individual exposure data obtained from subjects in Table 1. These data are approximate average values of BTEX and hydrogen sulfide in the area of each site are for personal sampling.

- Determining Hazard and risk descriptions of studied chemicals: Using the specifications chemicals BTEX compounds and H2S was to describe the risk. Then, risk rating for every substance was found according to exposure rate (exposure rating) and hazard classification. The achieved results of determining hazard and risk classification are presented in Table 1 . According to risk rating and determining the risk zone (red, yellow or green), the level of controlling and preventive measures were found.

\begin{tabular}{|c|c|c|c|c|c|c|c|}
\hline Risk Rating & $\begin{array}{c}\text { Hazard } \\
\text { Classification }\end{array}$ & $\begin{array}{c}\text { Exposure } \\
\text { Rating* }\end{array}$ & $\begin{array}{c}\text { OEL } \\
(\text { ppm) }\end{array}$ & $\begin{array}{l}\text { Standard } \\
\text { Deviation }\end{array}$ & $\begin{array}{l}\text { Concentration } \\
(\mathbf{p p m})\end{array}$ & Substance & Unit \\
\hline 1A & 1 & A & 0.5 & 0.01 & 0.66 & Benzene & \multirow{5}{*}{ NTA } \\
\hline $1 \mathrm{C}$ & 1 & $\mathrm{C}$ & 20 & 0.72 & 2.14 & xylene & \\
\hline 1B & 1 & $\mathrm{~B}$ & 20 & 0.22 & 10 & ethyl benzene & \\
\hline 1D & 1 & $\mathrm{D}$ & 100 & 0.03 & 1.4 & xylene & \\
\hline 1C & 1 & $\mathrm{C}$ & 1 & 0.004 & 0.2 & hydrogen sulfide & \\
\hline 1B & 1 & $\mathrm{~B}$ & 0.5 & 0.002 & 0.48 & Benzene & \multirow{5}{*}{ Kat Crocker } \\
\hline 1D & 1 & $\mathrm{D}$ & 20 & 0.005 & 81 & toluene & \\
\hline 1D & 1 & $\mathrm{D}$ & 20 & 0.006 & 0.27 & ethyl benzene & \\
\hline 1D & 1 & $\mathrm{D}$ & 100 & 0.036 & 2.62 & xylene & \\
\hline $1 \mathrm{~A}$ & 1 & $\mathrm{~A}$ & 1 & 0.12 & 1.7 & hydrogen sulfide & \\
\hline $1 \mathrm{~A}$ & 1 & $\mathrm{~A}$ & 0.5 & 0.004 & 0.82 & Benzene & \multirow{5}{*}{ MTBE } \\
\hline 1D & 1 & $\mathrm{D}$ & 20 & 0.03 & 0.96 & toluene & \\
\hline 1C & 1 & $\mathrm{C}$ & 20 & 0.52 & 2.63 & ethyl benzene & \\
\hline 1D & 1 & $\mathrm{D}$ & 100 & 0.09 & 1.23 & xylene & \\
\hline 1C & 1 & $\mathrm{C}$ & 1 & 0.0007 & 0.1 & hydrogen sulfide & \\
\hline 1A & 1 & $\mathrm{~A}$ & 0.5 & 0.79 & 3.7 & Benzene & \multirow{4}{*}{ distillation 100} \\
\hline 1A & 1 & A & 20 & 5.77 & 34.6 & toluene & \\
\hline $1 \mathrm{~A}$ & 1 & $\mathrm{~A}$ & 20 & 3.55 & 26.3 & ethyl benzene & \\
\hline 1D & 1 & $\mathrm{D}$ & 100 & 2.28 & 9.7 & xylene & \\
\hline
\end{tabular}




\section{Ergonomics International Journal}

\begin{tabular}{|c|c|c|c|c|c|c|c|}
\hline 1B & 1 & $\mathrm{~B}$ & 1 & 0.0005 & 0.6 & hydrogen sulfide & \\
\hline 1C & 1 & $\mathrm{C}$ & 0.5 & 0.0005 & 0.2 & Benzene & \multirow{5}{*}{ distillation 80} \\
\hline 1C & 1 & $\mathrm{C}$ & 20 & 1.44 & 7.35 & toluene & \\
\hline 1D & 1 & $\mathrm{D}$ & 20 & 0.46 & 1.23 & ethyl benzene & \\
\hline 1D & 1 & $\mathrm{D}$ & 100 & 0.56 & 2.33 & xylene & \\
\hline 1C & 1 & $\mathrm{C}$ & 1 & 0.004 & 0.2 & hydrogen sulfide & \\
\hline 1A & 1 & A & 0.5 & 1.11 & 4.93 & Benzene & \multirow{5}{*}{ distillation 70} \\
\hline $1 \mathrm{C}$ & 1 & $\mathrm{C}$ & 20 & 0.66 & 5.81 & toluene & \\
\hline 1B & 1 & B & 20 & 2.34 & 15.83 & ethyl benzene & \\
\hline 1D & 1 & $\mathrm{D}$ & 100 & 1.12 & 8.99 & xylene & \\
\hline 1C & 1 & $\mathrm{C}$ & 1 & 0.002 & 0.2 & hydrogen sulfide & \\
\hline $\mathbf{1 A}$ & 1 & A & 0.5 & 5.09 & 45.5 & Benzene & \multirow{5}{*}{ CR1 } \\
\hline 1A & 1 & $\mathrm{~A}$ & 20 & 3.26 & 38.3 & toluene & \\
\hline 1B & 1 & $\mathrm{~B}$ & 20 & 3.78 & 18.4 & ethyl benzene & \\
\hline 1C & 1 & $\mathrm{C}$ & 100 & 6.24 & 32.7 & xylene & \\
\hline 1C & 1 & $\mathrm{C}$ & 1 & 0.066 & 0.5 & hydrogen sulfide & \\
\hline $\mathbf{1 A}$ & 1 & $\mathrm{~A}$ & 0.5 & 7.92 & 80.5 & Benzene & \multirow{5}{*}{ ROP } \\
\hline $\mathbf{1 A}$ & 1 & $\mathrm{~A}$ & 20 & 9.6 & 161 & toluene & \\
\hline $\mathbf{1 A}$ & 1 & $\mathrm{~A}$ & 20 & 6.58 & 94.1 & ethyl benzene & \\
\hline $\mathbf{1 A}$ & 1 & $\mathrm{~A}$ & 100 & 7.41 & 151 & xylene & \\
\hline $\mathbf{1 A}$ & 1 & $\mathrm{~A}$ & 1 & 0.008 & 1.7 & hydrogen sulfide & \\
\hline
\end{tabular}

*Table 1: The results of measuring chemicals, exposure rating, hazard category and risk rating among the personnel's of different operational units.

$*$ A :At or Above OEL

$\mathrm{B} \leq: \mathbf{5 0 \%}>\mathbf{0} \%$ 100OEL

$\mathrm{C} \leq: 10 \% \%>500 \mathrm{EL}$

D :NIL - < 10\% OEL

*The relation between risk score and decreasing of lung functions: For finding the association between achieved risk score and lung functions deduction in the studied operational units, two red zones (A1 and B1) and yellow zone (D1, C1) of risk assessment for every chemicals was investigated with frequency percentage of three factors including FVC, FEV1/ FVC for every person by ANOVA. The results showed significant relation between risk assessment score and frequency percentage of the mentioned factors that the significance level $(p)$ for risk score and every one's of the factors was less 0.001. It was also demonstrated that the units having A1 risk rating among studied operational units, the many lung disorders (obstructive, restricted and complex) were found more.

\section{Discussion}

In order to assess the risk of occupational exposure to BTEX and $\mathrm{H}_{2} \mathrm{~S}$ combinations, the individual exposure of personnel's exposure was measured and monitored by use of NIOSH organization's standard methods in 30 different operational units. Then, to estimate the risk exposure, risk chemical descriptions for each of the study by using tables and parameters were defined in the risk assessment guide. Using two parameters and the risk of chemical exposure rate risk exposure level for each substance was obtained. Since the oil refining industry, the source of pollution per unit of fuel is the same, to improve the effectiveness of control measures and corrective highest risk factor achieved (qualitative score description the most hazardous risk) as the basis for action control and correction were considered.

The results also showed that Benzene, in comparison to other studied substances, had the most quality score of risk and was more hazardous for personnel's health. Since four studied substances were the most dangerous chemicals with certain and different distribution resources in ranking of chemicals hazardous level, the score 1 was registered for all of them. According to this, two achieved numbers of qualitative risk (IC, ID); yellow zone shows the hazard of risk an assessment for exposing to chemicals. So, those units that their risk scores were IA and IB, the level of controlling measures and monitoring chemicals in work place was defined as "urgent and arbitrary implementing of controlling 


\section{Ergonomics International Journal}

measures". For those received IC and ID, it was suggested doing continuous improvement and constant monitoring "of chemicals released in the atmosphere of work place. The almost risk rating of occupational exposure were found in ROP, distillation 100 and CR1 units respectively. Other units have different levels of risk rating. However, exposure risk of chemicals for all units was in red and yellow zones. The occupational exposure to oil combinations especially BTEX was not seen in Power plant, water and steam sub-units. Only occupational exposure to $\mathrm{H}_{2} \mathrm{~S} \mathrm{~S}$ was found in the mentioned places. Steinmaus, et al. [15] studied meta-analysis exposure to Benzene and the prevalence of Non Hutchins lymphoma (NHL) in petrochemical industries. Each found that exposure to Benzene and working in refinery cause to increase the relative risks of inducing NHL between the studied cases [15]. Baltrènas, et al. [16] the atmospheric concentration of BTEX in the vicinity of the crude oil refinery in the Baltic region studied. In this study it was found that the average concentration of $2.75 \mathrm{ppbv}$ of benzene from $2.12 \mathrm{ppbv}$ in rural areas to urban areas where traffic had been raised as a dominant source of BTEX emissions was different.

The study also showed that the concentration of benzene in the area around the refinery did not exceed $5 \mathrm{ppbv}$ and no significant change in the air quality around the refinery, crude oil, but the effect of this industry on the air quality was observed [16]. Ramirez, et al. [17] studied chronic risk of exposure to volatile organic compounds in the near zone of the biggest industrial site in Mediterranean area. 86 types of mentioned combinations were investigated in this study. No sign of carcinogenic impacts of exposure to VOCs found in their research. World risk of cancer morbidity was also found 3.3 cases in every 10000 people. The result was higher than the amount proposed by the WHO and USEPA [17] Liu, et al. [18] study of individual exposures and characteristics of carbonyl compounds and BTEX in 210 homes, studied in Beijing China. In this study it was found that the concentration of carbonyl internal and external sources of BTEX emissions were affected, as well as organic solvents in the glue decorations was new houses air pollution [18]. Chiang, et al. [19] studied the risk of exposure to inhalation $V D C_{s}$ distributed from facilities of steel industry. The seven combined VOCs include chloroform, carbon tetra chloride, 1, 1, 2- trichloroethane, trichloroethylene, tetrachloroethylene, benzene and ethyl benzene were selected to measure the risk of cancer.

The results showed that the four steel production process (including cooking, coke making, the form of hot, cold forming) the concentration of carbon tetra chloride and trichloroethylene were high and concentration of tetrachloroethylene in both cold and warm-up process, thus improving the quality of Current work and protection of workers necessary to reduce the risk of cancer resulted in [19]. Pandya, et al. [20] occupational exposure to VOCs in gasoline refinery fuel terminal assessed. In this study it was found that the overall level of Volatile Organic Compounds 0.1 to 1.97 mg cubic meter. 8-hour exposure to benzene, toluene and xylene isomers was low and less than the threshold limit values for exposure to gasoline compounds [20]. In another study Durmus Oglu, et al. [21] BTEX emissions and health risks discussed in the land fill. The results showed that BTEX emissions landfill was not introduced a threat to the health of workers. In addition, the air dilution BTEX emissions from landfill to guarantee enough to protection of the population in the neighborhood [21].

Based on mentioned necessities noticed in seventh and eighth steps, controlling and revising measures were defined and also the risk of occupational exposure to chemicals were managed according to results achieved from risk assessment and respiratory protection program (RPP) , the following controlling measures were implemented ; prevention from chemicals, poisonous gases and evaporates and also oil substances, isolation of chemicals injection pumps and installation of effective ventilation for sucking the air of isolated air , repairing and replacing old and defective compartments, use of local ventilation during manipulating chemicals in the units such as reverse osmosis, central workshop and other units, providing and using suitable respiratory protection devices, controlling industrial sewage made by units and vapors sent out, providing different educational courses about chemicals, their impacts, the methods of prevention and their control and so on. Order to make these measures effective, it is necessary to reassess risk of occupational exposure to chemicals. Moreover, for better prioritizing chemicals in the process of risk assessment in the industries with different distribution sources, it is better to recognize all substances that workers are exposed to them by sampling and analyzing the samples by use of such machines such as GC-Mass. Then, the proper decision about taking the priority of substances and their producing sources should be made.

\section{Conclusion}

In present study, the risk of occupational exposure to $\mathrm{H}_{2} \mathrm{~S}$ and BTEX were assessed by use of GPS method in various operational units of Abadan oil Refinement 
Company. According to the results, the risk of exposure to benzene is higher than other substances in operational units. After benzene, the highest rate of employee exposure risk related to hydrogen sulfide compounds, ethyl benzene, toluene and xylene, respectively. In those units that risk rating is more; the prevalence of decreasing lung functions and the risk of suffering from lung disorders is higher. In order to control the hazards of occupational exposure to studied chemicals and personnel protection , urgently controlling and continuous monitoring and constant improvement were defined, respectively, for the studied units with 1 and 2 risk assessment level priorities . Therefore, engineering control and technical and also managing measures were established. Furthermore, suitable respiratory protection devices were given to personnel's. Order to manage the risk and the implementation of the RPP (respiratory protection program) and to protect workers from the adverse effects of exposure to chemical substances, risk assessment of exposure is necessary.

\section{References}

1. Vermeire TG (2009) Evaluating uncertainties in an integrated approach for chemical risk assessment under REACH: more certain decisions?

2. Jahangiri M, Motovagheh M (2011) Health Risk Assessment of Harmful Chemicals: Case Study in a Petrochemical Industry. Iran Occupational Health 7(4): 4-10.

3. Fromme H, Albrecht M, Angerer J, Drexler H, Gruber L, et al. (2007) Integrated Exposure Assessment Survey (INES): exposure to persistent and bioaccumulative chemicals in Bavaria, Germany. Int J Hyg Environ Health 210(3): 345-349.

4. Seeley M, Tonner-Navarro L, Beck B, Deskin R, Feron $\mathrm{V}$, et al. (2001) Procedures for health risk assessment in Europe. Regulatory toxicology and pharmacology 34(2): 153-169.

5. Lilienblum W, Dekant W, Foth H, Gebel T, Hengstler J, et al. (2008) Alternative methods to safety studies in experimental animals: role in the risk assessment of chemicals under the new European Chemicals Legislation (REACH). Archives of toxicology 82(4): 211-236.

6. Grimm V, Ashauer R, Forbes V, Hommen U, Preuss TG, et al. (2009) CREAM: a European project on mechanistic effect models for ecological risk assessment of chemicals. Environmental Science and Pollution Research 16(6): 614-617.

7. Jalali M, Jalali S, Shafii Motlagh M, Mardi H, Negahban S, et al. (2014) Health risk assessment of occupational exposure to BTEX compounds in petrol refueling stations in Mashhad. J Neyshabur Univ Med Sci 1(1): 19-27.

8. Van-Wendel-De-Joode B, Brouwer DH, Vermeulen R, Van Hemmen JJ, Heederik D, et al. (2003) DREAM: a method for semi-quantitative dermal exposure assessment. Ann Occup Hyg 47(1): 71-87.

9. Occupational Safety and Health Division (2005) A Semi-Quantitative Method to Assess Occupational Exposure to Harmful Chemicals. Ministry of Manpower, Singapor, pp: 3-35.

10. Jahangiri M, Jalali M, Saeidi C, Mohammadpour $H$, Mardi H, et al. (2014) Health risk assessment of harmful chemicals in order to provide control guidelines: case study in a polyurethane foam industry. Occupational Medicine Quarterly Journal 5(4): 33-41.

11. Jahangiri M, Motovagheh M (2014) Health Risk Assessment of Harmful Chemicals: Case Study in a Petrochemical Industry. Iran Occupational Health Journal 5(4): 33-41.

12. Golbabaie F, Eskandari D, Rezazade Azari M, Jahangiri M, Rahimi M, et al. (2012) Health risk assessment of chemical pollutants in a petrochemical complex. Iran Occupational Health Journal 9(3): 11-21.

13. International Council of Chemical Associations (ICCA) (2011) Global Product Strategy: ICCA Guidance on Chemical Risk Assessment.

14. Kim MS, Kim JS, Kim BW (2012) Removal of gaseous toluene by using TiO2 film doped of $\mathrm{Ru}$-dye/Pt in a pilot scale photoreactor. Korean Journal of Chemical Engineering 29(5): 549-554.

15. Steinmaus C, Smith AH, Jones RM, Smith MT (2008) Meta-analysis of benzene exposure and non-Hodgkin lymphoma: biases could mask an important association. Occupational and Environmental Medicine 65(6): 371-378.

16. Baltrėnas $P$, Baltrènaitė $E$, Šerevičienè $V$, Pereira $P$ (2011) Atmospheric BTEX concentrations in the 


\section{Ergonomics International Journal}

vicinity of the crude oil refinery of the Baltic region. Environ Monit Assess 182(1-4): 115-127.

17. Ramírez N, Cuadras A, Rovira E, Borrull F, Marcé RM (2012) Chronic risk assessment of exposure to volatile organic compounds in the atmosphere near the largest Mediterranean industrial site. Environment International 39(1): 200-209.

18. Liu Q, Liu Y, Zhang M (2013) Personal exposure and source characteristics of carbonyl compounds and BTEXs within homes in Beijing, China. Building and Environment 61: 210-216.
19. Chiang HL, Lin WH, Lai JS, Wang WC (2010) Inhalation risk assessment of exposure to the selected volatile organic compounds (VOCs) emitted from the facilities of a steel plant. Journal of Environmental Science and Health, Part A 45(11): 1397-1405.

20. Pandya G, Gavane A, Kondawar V (2006) Assessment of occupational exposure to VOCs at the gantry gasoline terminal. J Environ Sci Eng 48(3): 175-182.

21. Durmusoglu E, Taspinar F, Karademir A (2010) Health risk assessment of BTEX emissions in the landfill environment. J Hazard Mater 176(1-3): 870877. 